\title{
Tradiciones peruanas: nuevas aproximaciones desde las ciencias médicas y la Psicología
}

\author{
GLADYS FLORES HEREDIA \\ Universidad Ricardo Palma \\ Lima, Perú \\ Contacto: gladys.floresh@urp.edu.pe
}

Son pocos los autores cuya obra logra vencer el paso del tiempo. En la literatura peruana existen algunos casos que podrían ilustrar esta afirmación. La poesía de José Santos Chocano (1875-1934) y la narrativa de Carlos Eduardo Zavaleta (1928-2011); si bien estos autores fueron en su momento referentes de posiciones poéticas o narrativas ejemplares, el curso de los años no los ha favorecido con la atención de especialistas, menos con el interés del amplio público lector. Pero existen autores que mantienen y renuevan, en los lectores, el interés por sus obras. Podríamos mencionar la obra del Inca Garcilaso de la Vega (1539-1616), Ricardo Palma (18331919) y César Vallejo (1892-1938) como una trilogía ejemplar de esta permanencia. Si centramos la atención en la obra del padre creador del género tradición, don Ricardo Palma, añadiríamos, incluso, que contra la crítica que hiciera González Prada y que 
actualizara Sebastián Salazar Bondy sobre el sentido romántico de las tradiciones, el interés académico y de los lectores continúa vigente, ¿y cómo probarlo? Sin duda, a través de las publicaciones académicas que se realizan respecto a su obra (tesis, libros, artículos), pero también mediante la referencia a congresos realizados sobre la vida y la obra del autor en las principales universidades del Perú y del extranjero.

El curso del siglo XX ha formado una sólida tradición de estudiosos de la obra de Ricardo Palma, desde la aproximación histórica de José Miguel Oviedo: Genio y figura de Ricardo Palma (1964), hasta el libro de Dora Bazán, Mujeres, ideas y estilo en las tradiciones de Palma (2001), pasando por la investigación de Fernando FloresZúñiga: Ricardo Palma y la tribuna parlamentaria. El tradicionista senador (1868-1873) (2019). Los diversos ángulos de la vida y la obra palmista han sido abordados. Pero la constante transformación de la sociedad del conocimiento exige también que se realicen análisis e interpretaciones que enriquezcan la tradición. Recordemos que leer a Palma en el siglo XX no es lo mismo que leerlo en el siglo XXI. No solo porque el mundo ha cambiado, sino también porque las preguntas con las que el lector contemporáneo se acerca a Palma no son las mismas.

El Palma de la Juventud. Revista de Estudiantes de la Universidad Ricardo Palma cree en la necesidad de formar profesionales de las diversas carreras con una clara vocación humanista y con un conocimiento de las fuentes de nuestra tradición cultural. Este número monográfico es una primera fotografía que reúne a los jóvenes investigadores que, desde las coordenadas del siglo XXI, escriben a partir del marco disciplinario de las ciencias médicas y los que lo hacen desde la Psicología. Se busca, en principio, enriquecer el conjunto de interpretaciones que se realizan de las tradiciones palmianas, pero también se llama la atención sobre la necesidad de 
los enfoques interdisciplinarios para liberar el texto de la cárcel de interpretaciones afincadas solo en el plano artístico y literario. Así, buena parte de los artículos ponen en escena aproximaciones bastante originales que, ordenándolas, podrían ofrecer una historia de la formación de la medicina en el Perú.

Atendamos tres artículos: «Del árbol al medicamento: la quina en las Tradiciones peruanas y el uso de la hidroxicloroquina en la actualidad» de Daniel Arauco; este alumno analiza la tradición «Los polvos de la condesa» y describe e interpreta cómo se empleaba la quina para ciertas dolencias en el Virreinato. Del mismo modo, Nadia Linares, en «Inicios de la ortopedia y traumatología peruana en la tradición "Brazo de plata" de Ricardo Palma», precisa que, a partir de la amputación del brazo del vigésimo tercer virrey del Perú, y de la necesidad de fabricarle una prótesis que lo reemplace, es que se puede evidenciar el surgimiento de la ortopedia y la traumatología en el Perú. Y en esta línea de hallazgos de formación disciplinaria en las Tradiciones, todas conectadas con el campo de la investigación en la historia de la Medicina, Mónica Siccha en su artículo: «Las parteras y los inicios de la ginecología en el Perú vistas en "Las brujas de Ica” de Ricardo Palma» propone describir y explicar cómo eran percibidas las parteras en el antiguo Perú y a partir de ello esclarecer su desarrollo y proceso de modernización. Anota la autora: «Ricardo Palma nos presenta en esta tradición a un personaje de nombre Na Manonga Lévano, quien es descrita como una bruja por poseer conocimientos sobre de qué forma realizar partos naturales evitando los riesgos que se podrían tener al momento de dar a luz, sin dañar el bienestar de la madre y del recién nacido. Así, Palma nos revela una de las posibles escenas que contribuye como un antecedente de la ginecología» (p. 127).

Un grupo importante de artículos aborda también la presencia de la medicina tradicional que practican los curanderos a través del 
suministro y dosificación de plantas como las borrajas, la hierba santa y el llantén. En ese sentido, el artículo de Adrián Calderón: "Actividad terapéutica del llantén en "El abad de Lunahuaná"», explica los usos terapéuticos del llantén y los efectos de esta planta en el organismo humano, señala el autor: «En el área de las ciencias de la salud, la relevancia de los productos naturales radica en las moléculas naturales producidas por organismos vivos tales como plantas, microorganismos, hongos, insectos e incluso animales. Estas moléculas presentan metabolitos secundarios, los cuales le otorgan características particulares, logrando que los estudios de estos productos naturales sean fundamentales para el desarrollo de la química orgánica y medicinal» (p. 117).

El segundo eje agrupa artículos centrados en la investigación psicológica. Quienes escriben toman las tradiciones palmianas como escenarios donde los personajes muestran ciertas inclinaciones psicológicas significativas para repensar algunos conceptos disciplinarios. Por ejemplo, a Betsy Godoy en el artículo: «El soporte y la dependencia emocional en "La camisa de Margarita" de Ricardo Palma» le interesa destacar cómo es que estas actitudes psicológicas (el soporte y la dependencia) continúan presentándose en la vida psíquica de la sociedad moderna, y cómo es que el desarrollo conceptual de la disciplina ha contribuido a su comprensión. Para Deisy Esquivel, la tradición «El médico inglés» es un texto clave para pensar la salud mental en el Perú, por lo menos desde el siglo XIX, y, sobre todo, para que, a partir de ella, se piense sobre los efectos psicológicos de la crisis sanitaria ocasionada por la COVID-19, y la necesidad de acompañamiento profesional para una conducción saludable. Propone la alumna que se debe desarrollar una política sanitaria para lograr «un óptimo bienestar emocional, psicológico y social» (p. 183) de camino al Bicentenario. 
Este muestrario nos hace saber de la importancia de nuevas preguntas y nuevos enfoques interdisciplinarios en torno a Palma. No es casual que en el presente número se publiquen dos artículos del estudiante Calderón Carrillo. A través de estos queremos mostrar que su autor se ha aproximado a la obra de Palma desde distintos frentes, en distintos momentos de su formación universitaria y con diferentes herramientas discursivas que le fueron transmitidas en los cursos de TCOE I y II respectivamente. De esta manera no solo muestra que su diálogo con la obra de Palma continúa, sino que también nos hace saber que existen diversas formas de acercarse a estudiar la obra palmiana. Estas relecturas desde las ciencias médicas, sus huellas formativas en prácticas ancestrales o los usos de plantas medicinales, así como la presencia de personajes que revelan la necesidad de fortalecer las instituciones que velen por el cuidado de la salud mental, son conclusiones que los lectores del siglo XXI extraen de estos textos del siglo XIX. Es así como Palma continúa vigente. Es así como nos reunimos para escribir y conversar sobre su vida y su obra, que es otra manera de reunirnos a dialogar sobre el pasado, el presente y el futuro de nuestra patria.

Para finalizar, quiero dejar por escrito mi agradecimiento al Dr. Iván Rodríguez Chávez, rector de la Universidad Ricardo Palma, por su fundamental apoyo a las iniciativas de investigación de alumnos y profesores. Estos dos primeros números de la revista de estudiantes El Palma de la Juventud son expresión material de su respaldo a la contribución intelectual del alumnado de nuestra casa de estudios. 